\title{
Identification of hydrogen and deuterium at the surface of water ice by reflection electron energy loss spectroscopy
}

\author{
F. Yubero ${ }^{1, a)}$ and K. Tökési ${ }^{2}$ \\ ${ }^{1}$ Instituto de Ciencia de Materiales de Sevilla, CSIC - U. Sevilla, C/Américo Vespucio 49, \\ E-41092 Seville, Spain \\ ${ }^{2}$ Institute of Nuclear Research of the Hungarian Academy of Sciences (ATOMKI), Debrecen, Hungary
}

(Received 12 June 2009; accepted 20 July 2009; published online 24 August 2009)

\begin{abstract}
A nondestructive method to distinguish between hydrogen $(\mathrm{H})$ and deuterium (D) at surfaces by reflection electron energy loss spectroscopy is presented. It is based on the analysis of the energy distributions of electrons elastically backscattered from surfaces containing $\mathrm{H}$ or $\mathrm{D}$. We consider standard and deuterated water ices as test surfaces. The recoil energy of the backscattered electrons depends on the atomic mass of the targets, and the contributions of $\mathrm{H}, \mathrm{D}$, and $\mathrm{O}$ to the measured spectra can be easily separated. The results of Monte Carlo simulations corroborate the experimental findings. (C) 2009 American Institute of Physics. [DOI: 10.1063/1.3202402]
\end{abstract}

The quantitative determination of the hydrogen $(\mathrm{H})$ content at surfaces is a subject of key importance in many technological fields. Polymers, carbon-based hard coatings, or new H-storage materials, may require such an analysis to improve the understanding of the processes that involve the presence of $\mathrm{H}$ atoms at surfaces. However, quantification of this element at the surface region (few nanometers depth) of a sample is not an easy task. Note that, for example, the direct evidence of $\mathrm{H}$ atoms does not show up in standard nondestructive surface analysis techniques such as X-ray photoemission or Auger spectroscopies. The quantification of $\mathrm{H}$ content at surfaces can be performed indirectly by High resolution electron energy loss spectroscopy. However, in this case, only those $\mathrm{H}$ atoms that contribute to the vibrational absorption spectra can be observed. Secondary ion mass spectroscopy and electron stimulated desorption are other indirect ways to determine $\mathrm{H}$ content through the analysis of the radicals present at surfaces. But these techniques have as drawbacks that they are destructive and their quantification is handicapped by strong matrix effects. $\mathrm{H}$ quantification with surface sensitivity is possible by means of ${ }^{1} \mathrm{H}\left({ }^{15} \mathrm{~N}, \alpha\right){ }^{12} \mathrm{C}$ nuclear reaction analysis, but this technique is not easily available.

The study of elastically backscattered electrons from surfaces by reflection electron energy loss spectroscopy (REELS) has been recently recommended as an alternative technique to quantify the $\mathrm{H}$ content at the surface of $a-\mathrm{C}: \mathrm{H}$ and polymer samples. ${ }^{1,2}$ This analysis is based on the fact that the energy loss of the incident electrons due to the recoil effect depends on the atomic mass of the particular atom present at the surface. The observed difference in recoil energies between $\mathrm{H}$ and $\mathrm{O}$ atoms (about $2 \mathrm{eV}$ for $1.5 \mathrm{keV}$ primary electrons) can be easily measured with standard electron spectrometers used in surface analysis. This procedure has also been used to check surface degradation in several polymers. ${ }^{3}$ Filippi and Calliari ${ }^{4}$ explored this strategy for the quantification of $\mathrm{H}$ at surfaces that contain other atoms such as O. Following the same principles but using higher electron kinetic energies, Vos and co-workers ${ }^{5-7}$ studied surface atomic compositions and vibrational properties.

${ }^{a)}$ Electronic mail: yubero@icmse.csic.es.
In this paper we go one step forward to explore if, with the same experimental approach, it is possible to differentiate between hydrogen and deuterium (D) in the surface region of a sample. This capability could be important for technological fields such as surface functionalization, where it is desired to distinguish between $\mathrm{H}$ and $\mathrm{D}$ at surfaces after interaction with labeled compounds. We have chosen normal and deuterated water as test labeled compounds because this polar molecule is of key importance in numerous surface reactions.

The experiments were performed in a system that consists of preparation and analysis chambers, linked by a transfer rod with a sample holder adapted to be cooled down to $200 \mathrm{~K}$. The base pressures in the preparation and analysis chambers were $2 \times 10^{-8}$ and $1 \times 10^{-9}$ mbar, respectively. The analysis chamber was equipped with a Leybold LH-10 electron spectrometer and a Perkin Elmer PHI-04-015 electron gun. Degassed deionized standard $\left(\mathrm{H}_{2} \mathrm{O}\right)$ and deuterated $\left(\mathrm{D}_{2} \mathrm{O}\right)$ water were used in the experiments. Several samples were prepared with either $\mathrm{H}_{2} \mathrm{O}$ or $\mathrm{D}_{2} \mathrm{O}$ admitted to the preparation chamber at $10^{-1}$ mbar for 1 min until a milky ice film was formed on the sample holder cooled to $200 \mathrm{~K}$. The substrates were then moved to the analysis chamber keeping the sample temperature fixed at $200 \mathrm{~K}$. Ice films deposited in this way are known to lack crystallinity. ${ }^{8}$

X-ray photoelectron spectroscopy (XPS) studies of the standard and deuterated ice samples were performed to confirm the chemical nature of the $\mathrm{H}_{2} \mathrm{O} / \mathrm{D}_{2} \mathrm{O}$ deposits. As expected, both water forms were identical to XPS characterization. The $\mathrm{C}$ contamination varied between $2-4$ at. $\%$ for different samples. The spectra were calibrated from the $\mathrm{O} 1 \mathrm{~s}$ signal at $537.6 \mathrm{eV}$. $^{9}$ The valence band of the water samples was characterized by the $1 b_{1}, 3 a_{1}$, and $1 b_{2}$ valence orbitals with binding energies of $11.0,13.5$, and $17.0 \mathrm{eV}$, respectively, in agreement with previous works. ${ }^{8-10}$

REELS analysis was performed using electron kinetic energies between 1000 and $1650 \mathrm{eV}$. The incident angle of the primary electrons with respect to the surface normal was $60^{\circ}$ and the backscattered electrons were detected at the surface normal (i.e., the scattering angle was $120^{\circ}$ ). The electron beam current was minimized to avoid sample damage during the measurements. Typically, the measuring time was 


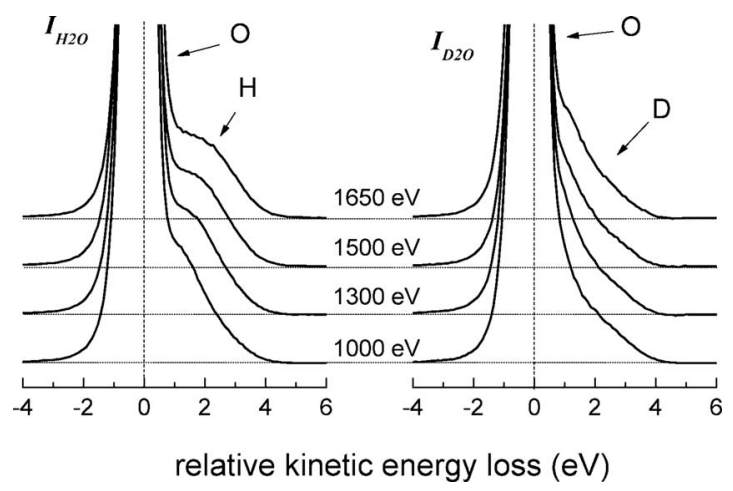

FIG. 1. Enlargement of the elastic part of the REELS spectra corresponding to $\mathrm{H}_{2} \mathrm{O}\left(I_{\mathrm{H}_{2} \mathrm{O}}\right)$ and $\mathrm{D}_{2} \mathrm{O}\left(I_{\mathrm{D}_{2} \mathrm{O}}\right)$ acquired with several primary energies.

of $\sim 1$ min. with electron beam currents below $1 \mu \mathrm{A} / \mathrm{cm}^{2}$. No water desorption was detected during the XPS or REELS measurements. This is consistent with the fact that thick water ice is rather stable against electron irradiation. ${ }^{11,12}$ The loss structure in the $\mathrm{H}_{2} \mathrm{O}$ and $\mathrm{D}_{2} \mathrm{O}$ REELS measurements were identical. Two main loss features, at $\sim 8 \mathrm{eV}$ and at $\sim 19 \mathrm{eV}$ energy loss were observed, corresponding to an exciton transition and a collective plasmon, respectively, in agreement with previous work. ${ }^{13,14}$

Figure 1 shows a blowup of the evolution of the $\mathrm{H}_{2} \mathrm{O}$ $\left(I_{\mathrm{H}_{2} \mathrm{O}}\right)$ and $\mathrm{D}_{2} \mathrm{O}\left(I_{\mathrm{D}_{2} \mathrm{O}}\right)$ elastic peaks, as the incident kinetic energy was varied between 1000 and $1650 \mathrm{eV}$. The spectra were aligned by setting the elastic-peak maximum to 0 energy loss. This maximum, for both $\mathrm{H}_{2} \mathrm{O}$ and $\mathrm{D}_{2} \mathrm{O}$ samples, is due to electron backscattering from $\mathrm{O}$ atoms. The weak peak for the $\mathrm{H}_{2} \mathrm{O}$ sample and part of the shoulder for the $\mathrm{D}_{2} \mathrm{O}$ sample on the low-kinetic energy of the main elastic peak is due to backscattering from $\mathrm{H}$ or $\mathrm{D}$ atoms. The experimental energy resolution, estimated from the full width at half maximum (FWHM) of the $\mathrm{O}$ elastic peak, was $0.7 \mathrm{eV}$. The energy differences between the $\mathrm{O}$ and H/D elastic peaks are due to the different recoil energies for electron backscattering from $\mathrm{O}$ and H/D, respectively. ${ }^{15}$ According to Fig. 1, $\left(\mathrm{H}_{2} \mathrm{O}\right.$ sample), the difference in recoil energy between the $\mathrm{H}$ and $\mathrm{O}$ contributions increases with the kinetic energy of the primary electrons. A similar effect is expected for the $\mathrm{D}_{2} \mathrm{O}$ sample. However, the energy resolution of our experimental setup and the smaller splitting between the $\mathrm{D}$ and $\mathrm{O}$ contributions does not allow the visualization of this behavior.

To highlight the difference between the electron reflected spectra on either $\mathrm{H}_{2} \mathrm{O}$ and $\mathrm{D}_{2} \mathrm{O}$, Fig. 2 shows the corresponding difference spectra, $I_{\mathrm{D}_{2} \mathrm{O}}-I_{\mathrm{H}_{2} \mathrm{O}}$, for each investigated energy. This is a convenient way to remove the elastic signal originated by electrons backscattered on $\mathrm{O}$ atoms to emphasize the H/D contributions to the spectra. Below $0.6 \mathrm{eV}$, where the elastic-peak contribution due to $\mathrm{O}$ scattering is important, only background noise is obtained. The H and D signals appear as negative or positive peaks, respectively. For a $1650 \mathrm{eV}$ primary-electron energy, the difference in recoil energy $\Delta E_{r}$ between $\mathrm{O}$ and $\mathrm{H} / \mathrm{D}$ is $2.4 / 1.1 \mathrm{eV}$ for the $\mathrm{H}_{2} \mathrm{O} / \mathrm{D}_{2} \mathrm{O}$ surfaces, respectively. $\Delta E_{r}$ decreases with decreasing incident energy. The inset in Fig. 2 shows the recoil energy as a function of incident electron energy for the two forms of water. Note that, in both cases, the experimentally observed recoil energies follow expectations according to a naive interpretation of electron scattering on static atom (dashed lines). ${ }^{7,8}$ It is also worth noting that the FWHM of

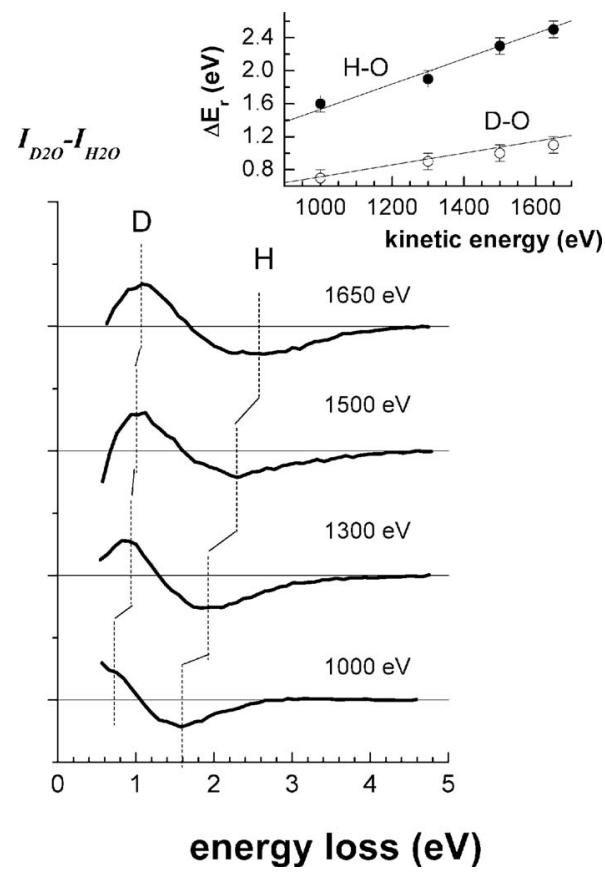

FIG. 2. Difference spectra $I_{\mathrm{D}_{2} \mathrm{O}}-I_{\mathrm{H}_{2} \mathrm{O}}$ for several kinetic energies. Inset: difference in recoil energy between $\mathrm{O}$ and $\mathrm{H}$ (full circles) or $\mathrm{D}$ (hollow circles).

the $\mathrm{H}$ peak is $1.5 \mathrm{eV}$. This value is larger than that for the $\mathrm{D}$ peak $(0.8 \mathrm{eV})$. We further note that the H/D elastic peaks are broader than the $\mathrm{O}$ peak. This is due to the Doppler broadening $^{16}$ affecting these peaks.

For a theoretical interpretation of our spectra, Monte Carlo (MC) simulations of the electron trajectories were performed. ${ }^{17}$ The electron penetration into the ice sample was approximated by a classical zigzag trajectory. We supposed that the studied sample is semi-infinite, homogenous and amorphous. The scattering point is where the electron changes its direction and/or energy. In our calculations both elastic and inelastic scattering events were taken into account and the calculations were stopped after the first inelastic event. Particular values of scattering angles of electrons in an individual scattering event are realized by random numbers describing the differential cross section for the target material. Differential cross sections for elastic scattering of electrons can be obtained from the partial-expansion method using Hartee-Fock-Slater wave functions. ${ }^{18}$ After each elastic scattering event, the recoil energy was evaluated from the classical energy and momentum conservation laws as described in Ref. 16. The energy distributions of elastically backscattered electrons from semi-infinite $\mathrm{H}_{2} \mathrm{O}$ and $\mathrm{D}_{2} \mathrm{O}$ samples were determined. We assumed, according to the experimental conditions, that the analyzer acceptance angle is $\pm 6^{\circ}$, which gives an effective scattering angle of $\theta_{o}$ $=120^{\circ} \pm 6^{\circ}$. During the MC simulation the following input data were used: atomic densities $\left[\rho_{\mathrm{H}_{2} \mathrm{O}}=0.92\right.$ and $\rho_{\mathrm{D}_{2} \mathrm{O}}$ $=1.02 \mathrm{~g} / \mathrm{cm}^{3}$ (Ref. 19) $]$ the corresponding elastic $\left[\lambda_{e}\left(\mathrm{H}_{2} \mathrm{O}\right)\right.$ $=81.12 \AA$ and $\lambda_{e}\left(\mathrm{D}_{2} \mathrm{O}\right)=81.35 \AA$ (Ref. 18) , inelastic mean free paths $\left[\lambda_{\text {in }}\left(\mathrm{H}_{2} \mathrm{O}\right)=44.0 \AA\right.$ and $\lambda_{\text {in }}\left(\mathrm{D}_{2} \mathrm{O}\right)=42.2 \AA$ (Ref. 20)] for electrons with $1500 \mathrm{eV}$ kinetic energy. This energy was selected, following the same criteria used in a previous papers, ${ }^{1,2}$ as a compromise between minimum electron damage and best elemental resolution. Finally, the average kinetic energies of the $\mathrm{H}(100 \mathrm{meV}), \mathrm{D}(40 \mathrm{meV})$, and $\mathrm{O}$ atoms 
MC simulation

$\left(\theta_{0}=120^{\circ}, 1500 \mathrm{eV}, \mathrm{H}_{2} \mathrm{O} / \mathrm{D}_{2} \mathrm{O}\right)$

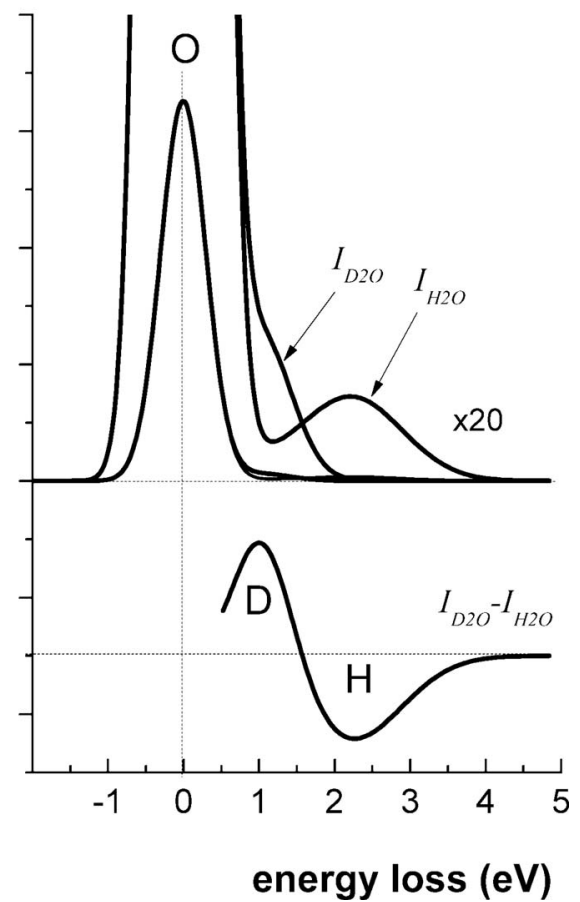

FIG. 3. Above: $\mathrm{MC}$ simulations corresponding to $1500 \mathrm{eV}$ backscattered electrons from $\mathrm{H}_{2} \mathrm{O}$ and $\mathrm{D}_{2} \mathrm{O}$ surfaces (primary energy $1500 \mathrm{eV}, \theta=120^{\circ}$ ). Below: Corresponding difference spectrum $I_{\mathrm{D}_{2} \mathrm{O}}-I_{\mathrm{H}_{2} \mathrm{O}}$. The signals coming from $\mathrm{H}, \mathrm{D}$, and $\mathrm{O}$ atoms are indicated.

(30 meV) were chosen to reproduce the experimental widths of the corresponding elastic contributions. The number of incident primary electrons was $10^{11}$.

Figure 3 shows results of MC simulations for $1500 \mathrm{eV}$ electrons backscattered at $\theta_{o}=120^{\circ}$ on $\mathrm{H}_{2} \mathrm{O}\left(I_{\mathrm{H}_{2} \mathrm{O}}\right)$ and $\mathrm{D}_{2} \mathrm{O}$ $\left(I_{\mathrm{D}_{2} \mathrm{O}}\right)$, under our experimental conditions. The difference spectrum $f_{\mathrm{D}_{2} \mathrm{O}}-f_{\mathrm{H}_{2} \mathrm{O}}$ is also shown. We note that, qualitatively, the spectrum from our MC simulation is similar to the experimentally observed spectrum and, in particular, the peak positions are similar to those observed experimentally for $1500 \mathrm{eV}$ electrons. The intensity of the $\mathrm{H}$ and $\mathrm{D}$ features is approximately the same, indicating that $\mathrm{H}$ and $\mathrm{D}$ (i.e., different isotopes) do not have different cross section for electron backscattering, as expected.
In summary, it has been shown that $\mathrm{H}$ and $\mathrm{D}$ can be easily distinguished at the surface of water ice using standard REELS measurements with 1000-1650 eV primary-electron energies, i.e., a surface analytical technique. Differences in recoil energies of the $\mathrm{O}-\mathrm{H}$ and $\mathrm{O}-\mathrm{D}$ atom pairs present in $\mathrm{H}_{2} \mathrm{O}$ and $\mathrm{D}_{2} \mathrm{O}$ have been found to agree with MC simulations. There are many possible applications of $\mathrm{H}$ and $\mathrm{D}$ detection by REELS. Among many others, this study opens the possibility of nondestructive studies of deuterium-labeled atoms present or adsorbed on surfaces. For example, studies of $\mathrm{H}$ incorporation into a polymer or carbon-based surface after plasma activation with gas mixtures with several labeled molecules containing $\mathrm{H}$ atoms.

F.Y. thanks the Spanish Ministry of Science and Education (Project CONSOLIDER-INGENIO CDS2008-0023, FUNCOAT) for financial support. K.T. was supported by the grant "Bolyai" from the Hungarian Academy of Sciences.

${ }^{1}$ F. Yubero, V. J. Rico, J. P. Espinós, J. Cotrino, and A. R. González-Elipe, Appl. Phys. Lett. 87, 084101 (2005).

${ }^{2}$ V. J. Rico, F. Yubero, J. P. Espinós, J. Cotrino, A. R. González-Elipe, D. Garg, and S. Henry, Diamond Relat. Mater. 16, 107 (2007).

${ }^{3}$ B. Lesiak, J. Zemek, and J. Houdkova, Polymer 49, 4127 (2008).

${ }^{4}$ M. Filippi and L. Calliari, Surf. Interface Anal. 40, 1469 (2008).

${ }^{5}$ M. Vos and M. R. Went, J. Electron Spectrosc. Relat. Phenom. 155, 35 (2007).

${ }^{6}$ M. R. Went and M. Vos, Appl. Phys. Lett. 90, 072104 (2007).

${ }^{7}$ M. Vos, M. R. Went, G. Cooper, and C. A. Chatziditriou-Dreismann, J. Phys. B 41, 135204 (2008).

${ }^{8}$ B. Baron and F. Williams, J. Chem. Phys. 64, 3896 (1976).

${ }^{9}$ K. Siegbahn, J. Electron Spectrosc. Relat. Phenom. 5, 3 (1974).

${ }^{10}$ M. J. Campbell, J. Liesegang, J. D. Riley, R. C. G. Leckey, J. G. Jenkin, and R. T. Poole, J. Electron Spectrosc. Relat. Phenom. 15, 83 (1979).

${ }^{11}$ H. Heide, Ultramicroscopy 14, 271 (1984).

${ }^{12}$ R. Souda, Surf. Sci. 511, 147 (2002).

${ }^{13}$ J. Daniels, Opt. Commun. 3, 240 (1971).

${ }^{14}$ J. M. Heller, R. N. Hamm, R. D. Birkhoff, and L. R. Painter, J. Chem. Phys. 60, 3483 (1974).

${ }^{15}$ D. Varga, K. Tőkési, Z. Berényi, J. Tóth, L. Kövér, G. Gergely, and A Sulyok, Surf. Interface Anal. 31, 1019 (2001).

${ }^{16}$ D. Varga, K. Tökési, Z. Berényi, J. Tóth, and L. Kövér, Surf. Interface Anal. 38, 544 (2006).

${ }^{17}$ K. Tőkési, D. Varga, L. Kövér, and T. Mukoyama, J. Electron Spectrosc. Relat. Phenom. 76, 427 (1995).

${ }^{18}$ F. Salvat and R. Mayol, Comput. Phys. Commun. 74, 358 (1993).

${ }^{19}$ Handbook of Chemistry and Physics, edited by D. R. Lide and (Chemical Rubber, Cleveland, 2003).

${ }^{20}$ S. Tanuma, C. J. Powell, and D. R. Penn, Surf. Interface Anal. 21, 165 (1994) 